\section{Editorial \\ COVID-19 Pandemic: Fear, Anxiety and Our Mental Health}

Naweed I. Syed

Creative Destruction Lab, Cumming School of Medicine, University of Calgary,

Calgary, Alberta-Canada

\section{OPEN@ACCESS}

As the saying goes: history repeats itself but for those who fail to learn lessons from it, they are often the worst off when the boomerang returns to strike them at the back. The 1918 influenza pandemic, caused by the HINI virus was perhaps the worst that our humanity had yet encountered. Its origin debatable (avian or otherwise), it infected over 500 million people across the globe within a year and wiped out almost 50 Million humans (40\% world population) from the face of the earth. A great deal of this death and demise owed its exitance to the fact that back then, neither did we have antibiotics nor the vaccines, and the infected ones were just left to die due to the lack of medical tools, technology/expertise. The lessons learned from that Spanish Flue compelled us to fight back against various infectious agents, and we develop antibiotics and vaccines which have since saved millions of lives worldwide. For instance, we developed Smallpox, Rabies, Hantavirus, Rotavirus, Dengue (at least for children), etc. vaccines but we have failed to produce effective vaccines for Ebola, Marburg virus, HIV, etc. In the meanwhile, we were hit by Severe Acute Respiratory Syndrome (SARS-COV - 2002), Middle East Respiratory Syndrome (MERS 2012, which had the highest mortality rate of $30-40 \%$ ), etc. Fortunately, we managed to prevent the spread of these viruses either by preventive measures or that the viruses could themselves not survive in our human body for
DOI:10.29052/IJEHSR.v8.i2.2020.47-49

Corresponding Author Email:

nisyed@ucalgary.ca

Received 07/04/2020

Accepted 11/05/2020

Published 01/06/2020

\section{(c) (i)}

(c) The Author(s). 2020 Open Access This article is distributed under the terms of the Creative Commons Attribution 4.0 International License (http://creativecommons.org/licenses/by/4.0/) an extended time period (SARS). The rapid infectious rate, shorter latency and faster recovery rates curtailed these viruses' long-term impact on our health and mental wellness. We were content with our efforts but we also let our guards down. In the meanwhile, the viruses and bacteria kept mutating to develop and adapted novel evolutionary traits to teach us yet another lesson. Enigmatically mutated, masterfully disguised and well-adapted COVID-I9 "terrorist" attack has since taken us by surprise. This virus originated in a bat whose well-designed immune system, coupled with the ability of this flying mammal, which could raise its body temperature to 40-4IOC during flight, equipped this virus to adopt to these otherwise harsh conditions that were tendered to it by its host. The virus took its fortified survival skills along as it moved to another nocturnal host and then finally took humans by surprise.

By the time the COVID-I9 infected humans, it had already equipped itself with twelve, novel amino acid spikes, which act like a harpoon, thus enabling it to dig into, and anchoring onto the soft lung tissue. Concurrently, it encapsulated and disguised those spikes with sugar coatings (carbohydrate molecules) - enabling it to completely avoid and fool the immune system. 
While our immune system failed to recognize this threat for almost two weeks, the virus in the meanwhile completely "hijacked" the host cells, and by the time the symptoms appeared, it was too late for the patients. This crafty and silent killer, with so many unknowns vis-à-vis it's the origin, makeup and whereabouts baffled scientists and left them completely bewildered. The high infection rates, with the infected showing no symptoms for two weeks, and the lack of vaccines, tools, or strategies to handle this threat, we have been left with fear, anxiety, paranoia, depression, panic, etc. The impact of this exogenous, pathogenic shock has not only impacted our well-being, but our mental health is further exacerbated by physical isolation and complete shutdown of the ways of our life; the one that we had become so accustomed to in the "global village". To make matters worse, financial crisis, job losses, income shortfalls, etc. have impacted the livelihood of just about everyone on this planet. While the grown-ups are struggling to make ends meet and to cope with this new paradigm shift in their working conditions, the school, colleges and university closures are leaving tremendous emotional scars on young minds. Taken together, there is ample plausible evidence to suggest that the most recent pandemic is exerting a tremendous impact on our mental health and wellness. Furthermore, recent emerging evidence has revealed that several neurological systems are also being perturbed in COVID-I9 infected patients, and these range from confusion, stroke to seizures, etc. The evidence is also emerging to suggest that while the virus is capable of breaching the blood-brain barrier to gain entrance into our brain, it also coaxes our already overactive and over-compensatory immune system is attacking its systems. This autoimmune shock has led to blood clots resulting from the "cytokine storm", thus rupturing blood vessels which lead to bleeding and stroke. The evidence is emerging to support the postulate that the infected patients are also exhibiting an altered state of mind, confusion, diminished sense of smell and taste, swelling/inflammation of the brain, tingling and numbness of extremities; the functions that are under the control of our nervous system.

The evidence to date thus strongly suggests that notwithstanding its impact on our economy and financial wellness etc., COVIDI9 is both physically and mentally harming our mental health - the impact of which will last for as long as we live. Whereas hopes for combating this virus with vaccines and other tools remain a thing of the future, and the social distancing being the only mitigation strategy at hand, the question thus arises as to what can be done now to mitigate and minimize its impact on our mental health? I think that the most important aspect to consider in this regard is to first understand how fear and anxiety manifest themselves in our mind, and how best to mitigate their longterm impact. We know that fear is the result of a threat or impending danger when the danger is real, definite and immediate; there is a clear and present object of the fear. The anxiety, on the other hand, results from perceived threat or danger; a diffuse, unpleasant, and a vague feeling of apprehension. Unfortunately, COVID-I9 with so many unknowns, it is both. It is creating fear with some knows, and anxiety is the context of the unknowns.

A three-part model of anxiety postulates that anxiety and the ensuing depression alter thoughts which in turn impact upon our feelings, hence influencing the behavior. The altered behavior then loops back onto our thoughts and the vicious cycle reverberates like a spinning wheel - exacerbating the output of our brain circuits for the worst. The ensuing changes to our neuronal circuits and synaptic connectivity leave a permanent mark on our brain, tagging neurons specifically in our amygdala, hippocampus and cortex. These circuits are essential for gauging our fear 
conditioning response which is so pivotal for our preparedness to any subsequent threats and survival. Their perturbation is likely to invoke either stronger or abated fight, flight, or freeze repertoire thus undermining our preparedness for any potential future threats. It is important to note that these changes are although not genetically manifested, the epigenetic triggers are nevertheless transferable to offspring. It is thus imperative that the individuals, families, loved ones and healthcare providers be vigilant - especially when it comes to young children and youth. One must look out for extreme shyness, isolation, lack of confidence (wiggly, jittery, shaky, high strung, unable to relax, etc.), the anticipation of bad things happening, excessive worries and apprehension about failure/future, fatigue, depression, paranoia, lack of zeal, zest and gusto, etc. The best way to manage these symptoms would to be control one's thoughts, making them optimistic, positive and constructive. This will then prevent fueling the engine of our feelings of apprehension, and thus alter our behavior towards ourselves and others. The best way to alter one's thoughts would be to exert control over them, allowing only essential information to go in, avoiding excessive news - both following and sharing. It is best to write down specific worries that one is preoccupied with and to have potential solutions for the envisaged apprehensions. One must also take up regular exercise, maintain a daily sleep pattern, read, write, eat healthy, pick up new hobbies, stay connected with family and friends (it will remind us that we are not alone), share and tell stories, catch up with old friends and meditate regularly. On the other hand, no matter what one must not let coronavirus conversations dominate one's life, and most importantly, reach out to those who are less fortunate and destitute.

In conclusion, it goes without saying that this is not the first time that we would have encountered such pandemics and it will not be the last. As a species, we humans are just as resilient as these viruses but more importantly, we possess a much advanced, more sophisticated and highly evolved brain; this is what we must protect at any cost!

\section{References}

I. Anderson ER, Hope DA. A review of the tripartite model for understanding the link between anxiety and depression in youth. Clin. Psychol. Rev. 2008;28(2):275-287.

2. Mahase E. Covid-I9: Mental health consequences of pandemic need urgent research, paper advises. BMJ. 2020: 369.

3. Torales J, O’Higgins M, Castaldelli-Maia JM, Ventriglio A. The outbreak of COVID-19 coronavirus and its impact on global mental health. Int J Soc Psychiatry. 2020:00207640209I52I2. 